\title{
Hydrothermal carbonization of fructose-effect of salts and reactor stirring on the growth and formation of carbon spheres
}

\author{
Dennis Jung $^{1}$ (D) - Gözde Duman ${ }^{2} \cdot$ Michael Zimmermann $^{3} \cdot$ Andrea Kruse $^{1}$ - Jale Yanik ${ }^{2}$
}

Received: 9 March 2021 / Revised: 12 July 2021 / Accepted: 14 July 2021

(C) The Author(s) 2021

\begin{abstract}
Hydrothermal carbonization (HTC) has become a promising technology for the production of hydrochar and carbon spheres. Several studies indicate a strong dependency of the reaction conditions on the sphere diameter. The usage of additives, such as salts, is one possibility to increase the size of the spheres. However, the growth mechanism which leads to larger particles is not fully understood. In this work, kinetic studies of HTC with fructose were performed with different salts as additives. The growth of the particles (the increase in size) has been compared to the formation rates (increase in yield) of hydrochar by using the reaction rate constants from the kinetic model. The results indicate that the acceleration of the growth rate is independent of the formation rate. It is therefore assumed that coagulation, as a growth mechanism, took place. With longer reaction times, the particles reached a stable particle size, independently from the added salts; therefore, it was assumed that the particles underwent some sort of solidification. The state of matter can therefore be described as an intermediate state between liquid and solid, similar to mesophase pitch. Experiments with a stirrer resulted in squashed particles, which supports the model, that the particles exhibit emulsion-like behavior.
\end{abstract}

Keywords Bioeconomy $\cdot$ Carbon spheres $\cdot$ Hydrothermal carbonization $\cdot$ Kinetic model

\section{Introduction}

\subsection{Motivation}

The challenge of transforming a fossil-based economy into a circular bioeconomy requires smart technologies, which are environmentally friendly and competitive on the market. In this context hydrothermal carbonization (HTC) is frequently discussed as a wet carbonization technology $[1,2]$. One important approach is using HTC of biomass as a pretreatment to produce carbon microspheres, or

Dennis Jung

Dennis.Jung@uni-hohenheim.de

1 Institute of Agricultural Engineering, Department of Conversion Technologies of Biobased Resources, University of Hohenheim, Garbenstrasse 9, 70599 Stuttgart, Germany

2 Department of Chemistry, Faculty of Science, Ege University, 35100 Bornova, Izmir, Turkey

3 Institute for Catalysis Research and Technology, Karlsruhe Institute of Technology (KIT), Hermann-von-Helmholtz-Platz 1, 76344 Eggenstein-Leopoldshafen, Germany so-called hydrochar, which can be converted into hard carbons for advanced applications, particularly utilization as anode material in lithium- or sodium-ion batteries [36]. A major potential of using HTC lays within the ability to tailor a desired morphology of spherical particles. Given this result, an examination of the formation and growth mechanism worths further attention. In this article, the term formation refers to the emergence of the hydrochar particles, independently from their geometric properties. The formation rate will be determined by the reaction rate constants of a kinetic model described in Section 2.5. In contrast, growth refers to the increase in particle size, which will be analyzed by SEM pictures. For the sake of reducing complexity, the reaction system starting from fructose will be studied. This is because fructose can be converted to HMF, which plays an important role during the formation of solid hydrochar particles during HTC.

\subsection{Background}

Regarding the formation mechanism of hydrochar: Patil et al. provided two fundamental studies that highlight the key role of hydroxymethylfurfural (HMF) in the formation of humins, a solid by-product during the hydrothermal 
conversion of monosaccharides [7, 8]. Kinetic studies showed that this concept is also valid at elevated temperatures (up to $210^{\circ} \mathrm{C}$ ) [9-11]; therefore, it can be assumed that humins are precursors of hydrochar. However, other substances, such as levulinic acid (LA) and formic acid (FA), are also likely to participate in the formation of hydrochar to a lower extent [12-14]. Recently, Shi et al. published two studies arguing that alpha-carbonyl aldehydes are the keyfunctional group driving the formation of humins $[15,16]$. In summary, it can be said that aldol-condensation reactions initially form oligomeric structures, which further precipitate and agglomerate to form spherical particles [17]. In the HTC literature, those particles are often referred to as secondary char [18], as they form via dissolved intermediates, in contrast, the term primary char refers to particles, which are the result of a solid-to-solid conversion pathway. The sum of both is called hydrochar; obviously, primary char cannot be formed when (dissolved) fructose is the feedstock; therefore, the terms secondary char and hydrochar are regarded as the same in this article.

The discussion about the growth mechanisms of carbon spheres is an ongoing debate. Whereas many studies are focused on the formation of the particles without additives [19-23], others make use of different kinds of additives, such as acids, bases, or salts [24-27], during the synthesis of the particles. There are several examples in which the usage of an additive results in remarkable larger particles $[9,28-34]$. Based on this observation, it is interesting to use additives as a tool to control the size of the particles. However, more knowledge is necessary to understand the mechanism by which the additives trigger the growth of the particles. To the best of our knowledge, the literature contains two hypotheses explaining the phenomenon:

(1) It is assumed that the additives have a catalytic impact on the reaction system, and therefore accelerate the polymerization and polycondensation reactions that form the particles, which further increases the size of the particles [28-31, 35]. It has to be noted that the authors used this hypothesis (1) to explain their results, but did not confirm it based on their results.

(2) Another way of explaining the effect of additives on the particle growth $[9,32,33]$ is founded on the DLVO (Derjaguin, Landau, Evert, Overbeek) theory. According to this, the additive, acting as an electrolyte, neutralizes the surface of the spheres, which decreases repulsive forces between the particles. In consequence, coalescence (the merging of two spheres) is accelerated and spheres become significantly larger than their references.

The second hypothesis seems somehow counter-intuitive as hydrochar is solid under standard conditions, therefore coalescence is not possible. To allow for this process, the particles have to behave similarly to droplets in emulsions. Due to technical limitations, it is difficult to provide indisputable evidence for this hypothesis during HTC. Until now nobody provided video footage of two merging carbon spheres after a collision under hydrothermal conditions. The observations of this process would undoubtedly prove the droplet-like properties of the particles. Until now only indirect methods can deliver hints in favor or against a certain conception. This is usually done by stopping the reaction through quenching, separating solid and liquid phase, and investigating a dried sample of the carbon spheres. But what are the arguments in favor of coagulation of emulsion-like droplets? A first hint can be found in scanning-electron-microscopy (SEM) of different carbon spheres, displaying them in a state of partial coagulation, where two or more spheres have started merging without completing it [9, 29, 36-38]. Additionally, in a previous publication it has been observed that the growth of the spheres continued after the conversion of the main building block of the spheres (HMF); thus, coalescence very likely took place [9].

\subsection{Objective}

The purpose of this study is to investigate the formation and growth of carbon spheres under the influence of three different chloride salts, representing the additives. The aim is to compare a kinetic model with the growth of the particles, to evaluate which of the above-mentioned hypothesis is suitable to explain the results. Furthermore, if hypothesis 2 is true, and the particles exhibit emulsionlike properties they are likely to be vulnerable to mechanical stress. Therefore carbon spheres were produced with and without reactor stirring. The authors expect crushing and smearing of the carbon spheres by the stirrer, and therefore another hint that confirms their emulsion state of matter.

\section{Material and methods}

\subsection{Materials}

Fructose and calcium chloride $\left(\mathrm{CaCl}_{2}\right)$ (dihydrate) were purchased from VWR Chemicals, iron(III) chloride $\left(\mathrm{FeCl}_{3}\right)$ (hexahydrate) from Sigma-Aldrich, and potassium chloride $(\mathrm{KCl})$ from Merck. In order to get different properties of the salts, an alkali, an alkaline earth and a transition metal chloride is used.

\subsection{Hydrothermal carbonization without stirring}

The experiments were carried out in 12-ml micro-autoclaves, which were filled with $8.54 \mathrm{~g}$ of $0.5 \mathrm{M}$ fructose solution. 
Either $\mathrm{KCl}, \mathrm{CaCl}_{2}$ or $\mathrm{FeCl}_{3}$ was added to the solution with a concentration of $0.025 \mathrm{M}$. Additionally experiments with $\mathrm{KCl}$ were performed with $0.1 \mathrm{M}$, giving a solution with the same ionic strength as $\mathrm{CaCl}_{2}$ with $0.025 \mathrm{M}$. The ionic strength was calculated by using only the positive charged ions [39]. In total 5 autoclaves were put on a rack and heated in the oven chamber of a disused gas chromatograph to $200{ }^{\circ} \mathrm{C}$. Prior to the experiment the heating time was measured with an autoclave that carries a thermocouple and takes approximately $24 \mathrm{~min}$. Therefore, after $24 \mathrm{~min}$ of heating, the first autoclave was quenched, corresponding to the reaction time of $0 \mathrm{~min}$. In the beginning, the reactors were quenched in 5-min intervals followed by larger intervals. The reactors were quenched in water at $20{ }^{\circ} \mathrm{C}$. After quenching the autoclaves were opened, the slurry was filtrated via vacuum filtration to separate solid and liquid. An aliquot of the liquid was taken and afterwards, the autoclaves were rinsed with distilled water to collect the entire solid fraction. The solid was washed with approximately $100 \mathrm{ml}$ of distilled water and dried at $105^{\circ} \mathrm{C}$ overnight and weighted. The yield has been calculated gravimetrically.

\subsubsection{Reproducibility}

Prior to the experiments, the reproducibility of the autoclaves was tested. Five autoclaves were tested with identical conditions $\left(T=200{ }^{\circ} \mathrm{C}, t=120 \mathrm{~min}\right)$, the hydrochar yield was $33.4 \pm 0.4$ wt. $\%$. Experience from pre-trials showed that the repetition of an experiment in most cases resulted in a deviation lower than $1 \mathrm{wt} . \%$ for the yield, for this reason, the experiments were only performed once.

\subsubsection{Experimental error}

The error of the hydrochar and HMF concentration has been calculated based on an uncertainty of the reaction time of $\pm 10 \mathrm{~s}$ (horizontal error). The corresponding error was computed by calculating the concentration of the two species at a given time point and $5 \mathrm{~s}$ later using the kinetic model presented in Section 2.5. The difference between both values was doubled to calculate the error. Between 0 and 30 min of reaction time, the error was between 2 and $5 \%$; between 30 and $180 \mathrm{~min}$, the error was $\leq 0.5 \%$. The uncertainty related to the reaction temperature is $\pm 1{ }^{\circ} \mathrm{C}$, however, an estimation of the error was not possible because only one reaction temperature was used. The yield of the hydrochar shows a slight error from the model line, which is not present for the HMF concentration (Fig. 2). This is due to losses during the rinsing of the reactor and the filtration of the slurry after quenching. It has been assumed that the uncertainty from this procedure is a maximum of $0.01 \mathrm{~g}$, resulting in an error of $2.2 \%$ of the hydrochar yield.

\subsection{Hydrothermal carbonization with stirring}

Hydrothermal carbonization experiments with a stirring reactor were performed in a $0.45-1$ stainless steel autoclave with an external magnetic stirrer (Buchi Glassuster Limbo model). The temperature of the reactor was controlled by a jacket which consisted of a heating and water-cooling system with PID controller. In a typical run, $150 \mathrm{~mL}$ of $0.5 \mathrm{M}$ fructose solution with $0.025 \mathrm{M}$ salts $\left(\mathrm{CaCl}_{2}\right.$ and $\mathrm{FeCl}_{3}$ ) was loaded into the reactor and the reactor was purged with nitrogen $\left(\mathrm{N}_{2}\right)$ gas. The jacket was heated at a rate of $10{ }^{\circ} \mathrm{C} / \mathrm{min}$ to desired reactor temperature $\left(200{ }^{\circ} \mathrm{C}\right)$ and held at that temperature for $60 \mathrm{~min}$. The reactor was stirred at a constant speed of $100 \mathrm{rpm}$ during HTC run. The agitator type was an anker (Fig. 1). For pure water, the system is characterized by the numbers in Table 1. After $60 \mathrm{~min}$, the reactor was cooled down until it reached room temperature. Hydrochar was recovered from the reactor residue by vacuum filtration. Hydrochar was then dried overnight at $105^{\circ} \mathrm{C}$. It has to be noted that experimental results produced by stirring were not subject of kinetic modeling, but only evaluated regarding the morphology of the hydrochar particles.

\subsection{Analytics}

\subsubsection{Carbon content}

The carbon content of the solid was determined with an Elemental Analyzer (Euro EA-CHNSO) from Hekatech by dynamic, spontaneous combustion and subsequent chromatographic separation.

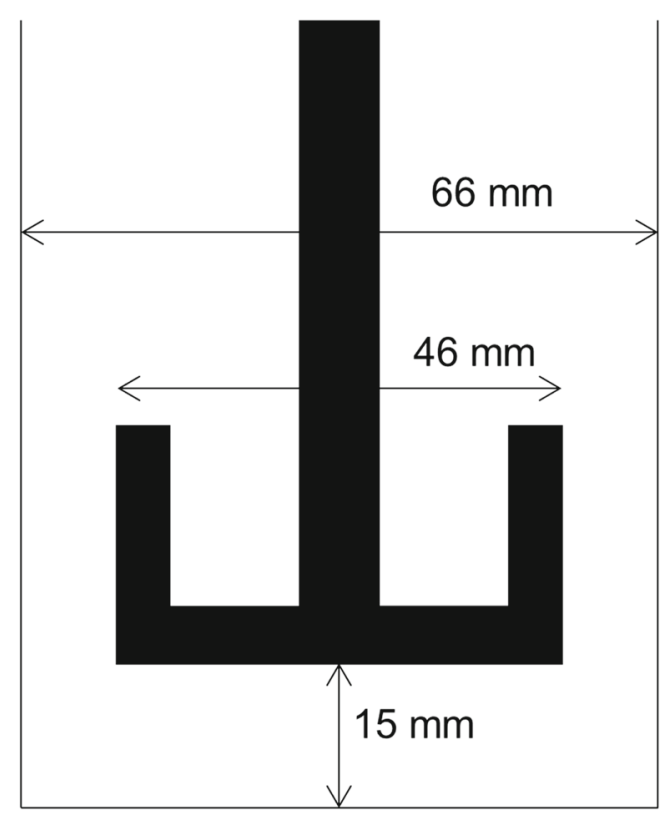

Fig. 1 Sketch of the agitator in the reactor with relevant dimensions 
Table 1 Properties of the mixing system

\begin{tabular}{llllll}
\hline Property & Sign & Value & Unit & Equation & Source \\
\hline Diameter reactor & $D$ & 0.066 & $\mathrm{~m}$ & & \\
Diameter of agitator & $d$ & 0.046 & $\mathrm{~m}$ & & \\
Stirring rate & $n$ & 1.67 & $\mathrm{~s}^{-1}$ & & \\
Density* & $\rho$ & 865 & $\mathrm{~kg} \mathrm{~m}^{-3}$ & From table & {$[40]$} \\
Kinematic viscosity* & $v$ & $1.56 \mathrm{E}-07$ & $\mathrm{~m}^{2} \mathrm{~s}^{-1}$ & From table & {$[40]$} \\
Reynold number & $R e$ & $2.3 \mathrm{E}+04$ & $(-)$ & $R e=n d^{2} / v$ & {$[41]$} \\
Circumferential speed & $w$ & 0.241 & $\mathrm{~m} \mathrm{~s}^{-1}$ & $w=\pi d n$ & {$[41]$} \\
Newton number & $N e$ & 0.35 & $(-)$ & From table & {$[42]$} \\
Power requirement & $P$ & $2.9 \mathrm{E}-04$ & $\mathrm{~W}$ & $P=N e \rho n^{3} d^{5}$ & {$[41]$} \\
Force at the agitator & $F$ & $1.2 \mathrm{E}-03$ & $\mathrm{~N}$ & $F=P / w$ & {$[41]$} \\
\hline
\end{tabular}

* Of water at $200^{\circ} \mathrm{C}$

\subsubsection{Liquid phase}

HPLC analysis is carried out using a Shimadzu Prominence System equipped with a refractive index detector and a BioRad Aminex HPX-87H column $(300 \times 7.8$ mm I.D. $)$. The measurements are performed isocratically with $4 \mathrm{mM}$ aqueous sulfuric acid $\left(\mathrm{H}_{2} \mathrm{SO}_{4}\right)$ at a flow rate of $0.6 \mathrm{~mL} / \mathrm{min}$ and an oven temperature of $35{ }^{\circ} \mathrm{C}$. The salt concentration was determined by measuring the concentration of potassium, calcium and iron with ICP-OES (Agilent 715) by injection of a diluted sample $1: 10 \mathrm{v} / \mathrm{v}$ with $1 \% \mathrm{HNO}_{3}$.

\subsubsection{Scanning electron microscopy}

Scanning electron microscopy (SEM) was performed with a GeminiSEM 500 from Zeiss (software: SmartSEM Version 6.01) with a thermal Schottky field emitter cathode. The variable pressure system allows pressures down to $500 \mathrm{~Pa}$ which is applied in the case of non-conductive samples. The pictures here were recorded with an Everhart-Thornley (SE) detector and a variable pressure secondary electrons (VPSE) detector. The acceleration voltage was set between 0.7 and $3 \mathrm{keV}$.

\subsubsection{Determination of particle size}

The diameter of the carbon spheres was measured based on the SEM pictures using the software ImageJ distribution Fiji. In the case of merged spheres, the spherical subunits were measured, as far as the spherical shape was identifiable. Depending on the resolution and the size of the particles the diameter of approximately 100-650 particles was measured.

\subsection{Kinetic model}

The reaction network has been modeled by a kinetic model, which is represented in Fig. 2. It consists of the main reactions that are recognized for the hydrothermal conversion of fructose, such as the isomerization to glucose [43] and the dehydration to HMF [44]. The reverse reaction from glucose to fructose was neglected because the optimization tool in MATLAB (Section 2.6) fitted the corresponding reaction rate constant to 0 in all cases. The reaction pathway from fructose to furfural is scientifically recognized but has not been investigated deeply since it is of minor quantitative relevance [45]. Fusaro et al. describe a reaction pathway that forms furfural besides from formaldehyde [46]. The formation of formaldehyde from fructose is also poorly described, however formic acid (FA) is known to appear in a higher molecular ratio than 1:1 compared to levulinic acid (LA) [47], which means that there is at least a second source besides from the rehydration of HMF (reaction $k_{6}$ ). For this reason, it was assumed the surplus of FA is related to the formation of furfural.

The "Residue" is the sum of all substances, which were not measured, and was calculated on a molar carbon-balance. For that, the total carbon concentration for all the chemical species in Fig. 2 was subtracted from the initial amount of carbon. The molar carbon concentration was calculated by multiplying the molar concentration of the species times the

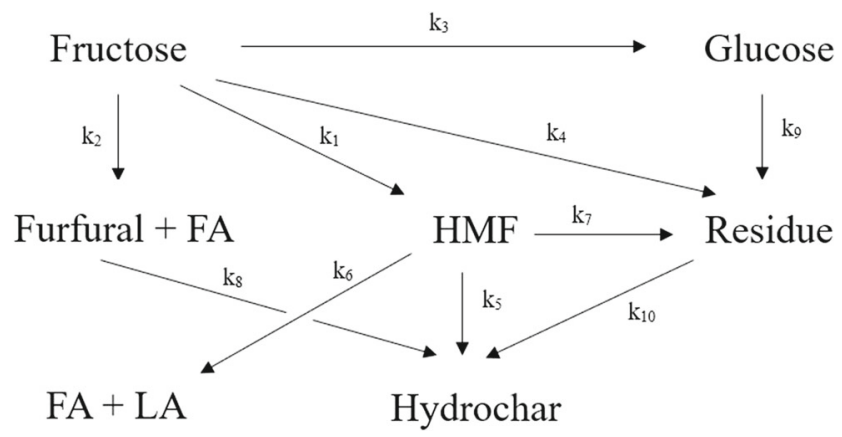

Fig. 2 Schematic representation of kinetic model. HMF, hydroxymethylfurfural. FA, formic acid; LA, levulinic acid 
number of carbon atoms in the corresponding species. This kind of connection to form "Residue" is appropriate since its precursor all consist of $\mathrm{C}_{6}$ molecules. The reaction network was implemented in a system of differential equations (SDE) (Eq. 1-8).

$$
\begin{aligned}
& \frac{d[\text { Fructose }]}{d t}=-\left(k_{1}+k_{2}+k_{3}+k_{4}\right)[\text { Fructose }] \\
& \frac{d[\text { Glucose }]}{d t}=k_{3}[\text { Fructose }]-k_{9}[\text { Glucose }] \\
& \frac{d[H M F]}{d t}=k_{1}[\text { Fructose }]-k_{5}[H M F]-\left(k_{6}+k_{7}\right)[H M F]
\end{aligned}
$$

$$
\begin{aligned}
\frac{d[\text { Hydrochar }]}{d t}= & k_{5}[\text { HMF }]+k_{8}[\text { Furfural }] \\
& +k_{10}[\text { Residue }]
\end{aligned}
$$

$\frac{d[F A]}{d t}=k_{2}[$ Fructose $]+k_{6}[H M F]$

$\frac{d[L A]}{d t}=k_{6}[H M F]$

$\frac{d[\text { Furfural }]}{d t}=k_{2}[$ Fructose $]-k_{8}[$ Furfural $]$

$$
\begin{aligned}
\frac{d[\text { Residue }]}{d t}= & -k_{4}[\text { Fructose }]+k_{7}[H M F]+k_{9}[\text { Glucose }] \\
& -k_{10}[\text { Residue }]
\end{aligned}
$$

The hydrochar yield, which was gravimetrically measured, is transformed into molar concentration $\left(\mathrm{mol} \mathrm{L}^{-1}\right)$ using the molecular weight of $108.1 \mathrm{~g} \mathrm{~mol}^{-1}$ [9]. This is derived by the simplified stoichiometry for hydrochar formation displayed in Eq. 9. It is assumed that the major fraction of hydrochar is produced by the polycondensation of HMF [7]. As a consequence every reaction of HMF with itself splits off one water molecule. This means that for larger oligomers, the amount of eliminated water molecules is approximately equal to the amount of HMF molecules that formed the oligomer, thus allowing for the approximation given in Eq. 10. The model therefore assumes that one hydrochar-unit has the molecular weight of $108.1 \mathrm{~g} \mathrm{~mol}^{-1}$, although the total hydrochar particle has a higher molecular weight. Equation 10 displays the molecular weight of HMF, a hydrochar-unit and $\mathrm{H}_{2} \mathrm{O}$, respectively in line with Eq. 9 .

$n \mathrm{HMF} \rightarrow \mathrm{Hydrochar}+(n-1) \mathrm{H}_{2} \mathrm{O}$

$$
126.1 \mathrm{~g} \mathrm{~mol}^{-1}=108.1 \mathrm{~g} \mathrm{~mol}^{-1}+18 \mathrm{~g} \mathrm{~mol}^{-1}
$$

The concept has been used successfully for the kinetic modeling of HTC in previous publications [9-11]. The reaction of HMF to hydrochar has been modeled as a firstorder reaction, although an order between 1 and 2 has to be expected [11]. For the sake of simplicity, this aspect has been neglected, as the cited publication shows that the reaction order is not a constant value, but varies between 1 and 2 depending of the concentration and reaction time.

\subsection{Calculation procedure}

The calculation of the kinetic parameters was done with MATLAB R2020a. The SDE were numerically integrated with ode 45 using the concentration of all substances at $t=$ $0 \mathrm{~min}$. The kinetic constants were adjusted using lsqnonlin from the Optimization Toolbox.

\section{Results}

The first section of the results deals with the morphological aspects of the hydrochar particles. In Fig. 3, SEM pictures display the particles right after the heating phase of the reaction $t=0 \mathrm{~min}$. Especially, hydrochar produced in the presence of $\mathrm{KCl}$ appears smaller than those produced in the presence of $\mathrm{CaCl}_{2}$ and $\mathrm{FeCl}_{3}$. In comparison to this early stage, it can be shown that this difference is almost not visible anymore $180 \mathrm{~min}$ later (Fig. 4). Based on those SEM pictures the sphere diameter of the particles was measured to estimate the mean diameter for the samples. The plot of the sphere diameter as a function of reaction time is given in Fig. 5. The $y$-axis of the figures is given on a logarithmic scale, allowing for a full and lucid representation of the results. This distribution function right to the Box-plots is based on a log-transformed normal distribution, which was more accurate in representing the data than a normal distribution. For both $\mathrm{KCl}$ samples and the $\mathrm{CaCl}_{2}$ it can be shown that at the beginning of the reaction at $t=$ $0 \mathrm{~min}$, the spheres are remarkably smaller compared to the time points $20-180 \mathrm{~min}$, and vary between $0.5 \mu \mathrm{m}$ and few micrometers. Only for $\mathrm{FeCl}_{3}$ the first time point displays rather large particles, which are in the same order of magnitude as the following. In total it can be said that the overwhelming majority of the spheres is in a range between 1 and $10 \mu \mathrm{m}$. However, the longer the reaction takes place, the higher is the chance for the emergence of very large particles with diameter $>20 \mu \mathrm{m}$.

In Fig. 6, the sphere diameter at $t=0 \mathrm{~min}$ is represented as a function of the salts, which is a double-representation of the results in Fig. 5. However, it is important for the discussion, to highlight the differences between the samples, especially at the beginning of the reaction. Both $\mathrm{KCl}$ samples show remarkable differences, whereas $\mathrm{KCl}$ at $0.1 \mathrm{M}$ and $\mathrm{CaCl}_{2}$, both having the same ionic strength, are rather similar. The particles produced in the presence of $\mathrm{FeCl}_{3}$ have the largest diameter compared to the other variants. 
Fig. 3 SEM pictures of carbon spheres at $t=0 \mathrm{~min}$ for four different salts. Magnification: $\times 1000$
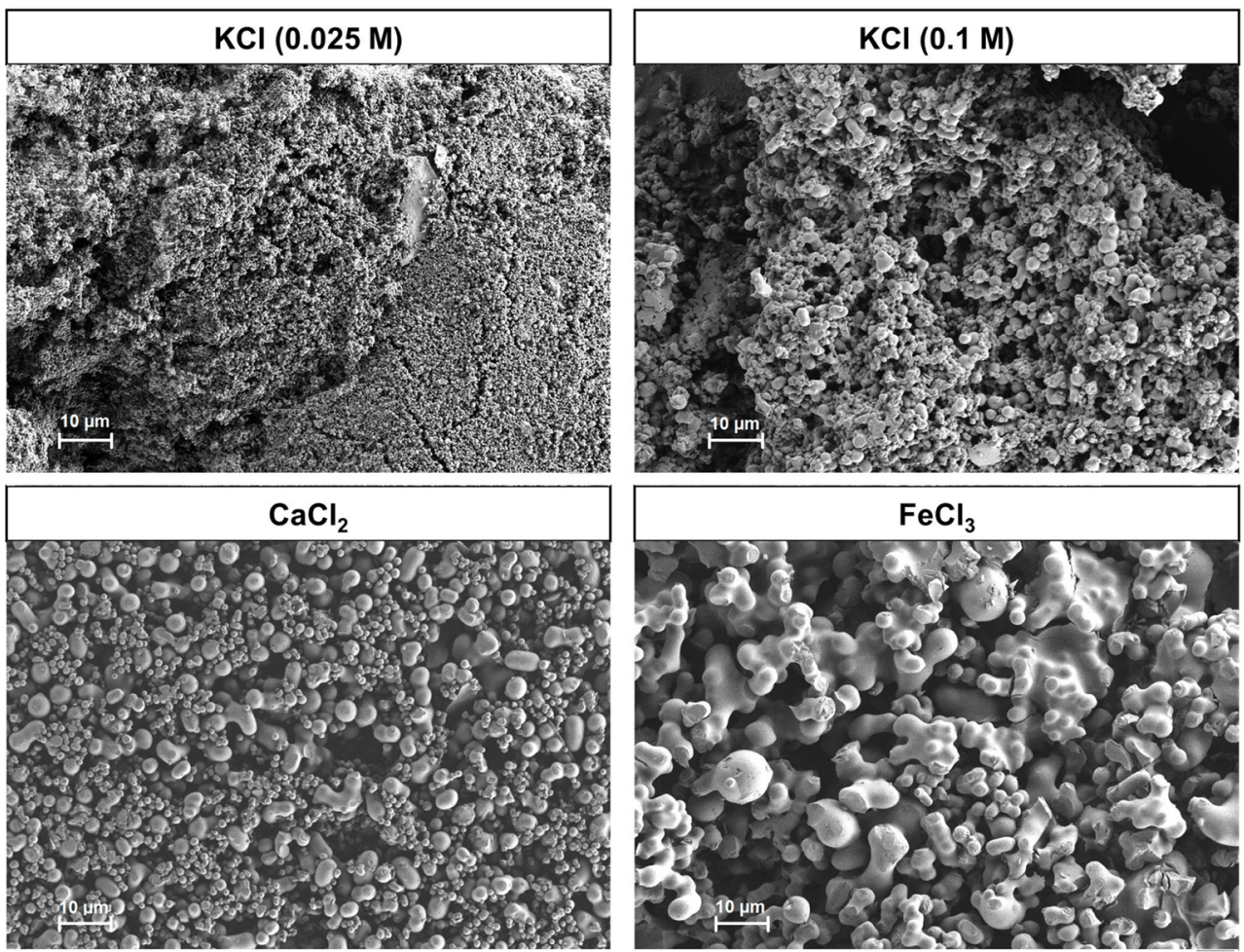

\subsection{Carbon content of hydrochars}

The carbon content of the hydrochars is displayed in Table 2. Two samples for each series of experiments have been chosen, one at the early stage of the reaction and one at the end. The carbon content is in a range between 64.8 and $67.9 \%$.

\subsection{Kinetic model}

The results from the kinetic model are represented by the reaction rate constants in Table 3 and the model lines in the concentration-time plot in Fig. 7. Because the conversion of fructose mainly takes place during the heating phase, which is not covered by the kinetic model, the rate constants
Fig. 4 SEM pictures of carbon spheres at $t=180 \mathrm{~min}$ for four different salts. Magnification: $\times 1000$
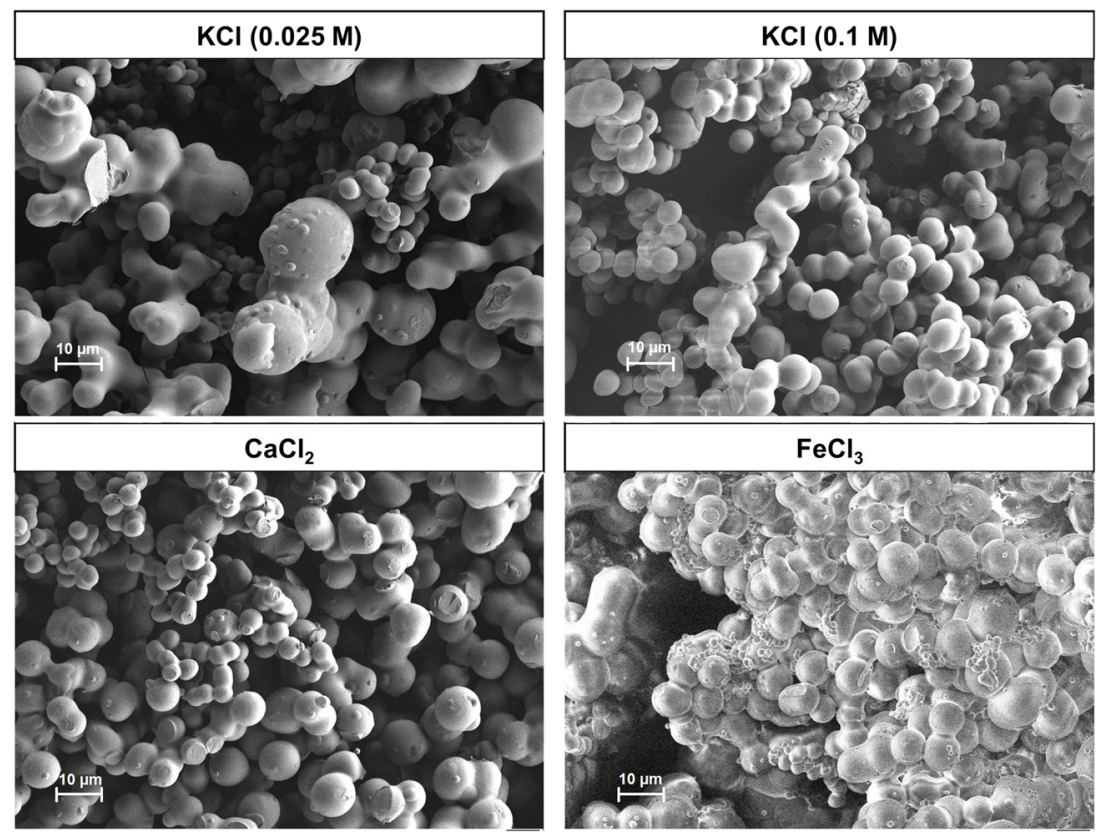

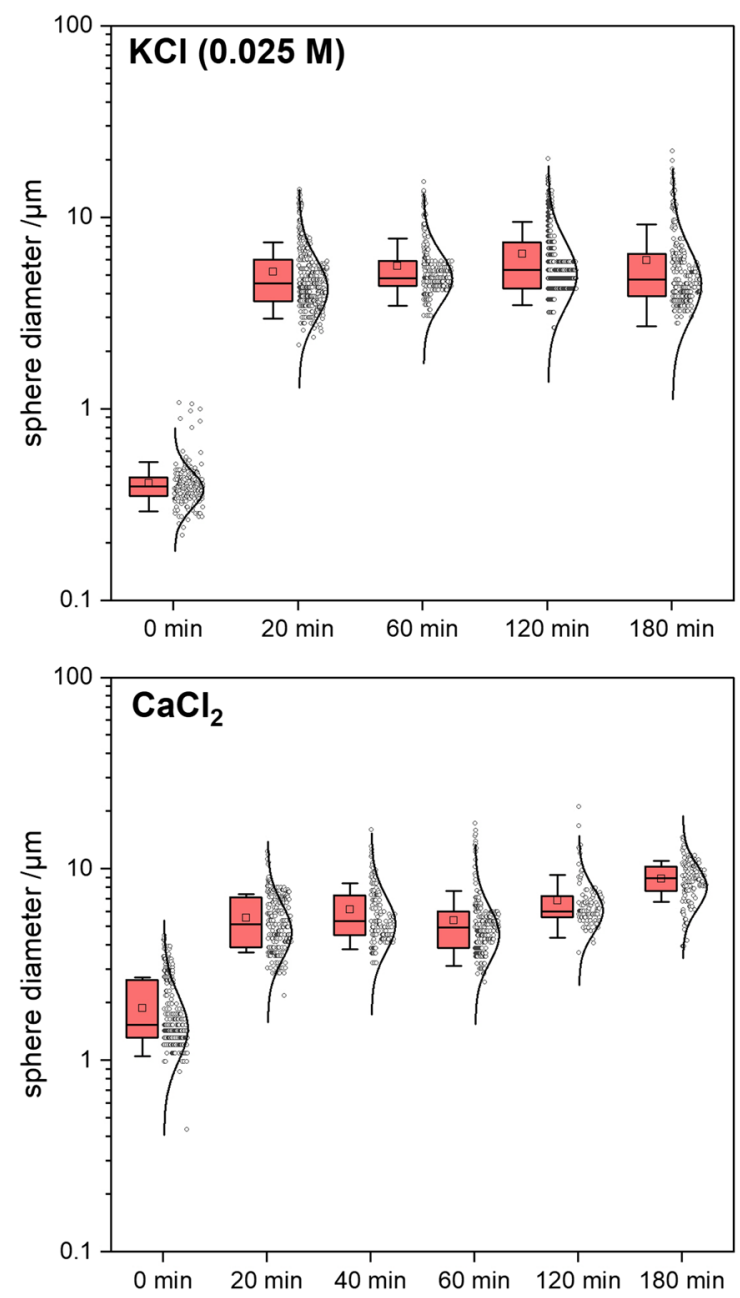

Fig. 5 Box-plot of the sphere diameter measured at different time points for four different salts. The height of the box-plot displays the lower 25 and upper 75 percentiles. The little square shows the mean value. The horizontal line in the box shows the median. The upper

$k_{1}-k_{4}$ are expected to have a high error and are therefore not reliable. Furthermore, for the $\mathrm{FeCl}_{3}$ experiments fructose could not be detected in the process water, therefore the rate constants were not calculated. The most important values are $k_{5}$ and $k_{6}$, representing the major reactions of HMF to hydrochar and LA+FA, respectively. Those values can be expected to have the highest degree of accuracy since the concentration of the substance is significantly high enough so that the relative error is smaller. The rate constants $\left(k_{5}\right)$ for both $\mathrm{KCl}$ experiments have little difference, similar to $\mathrm{CaCl}_{2}$ where they are slightly higher. In the presence of $\mathrm{FeCl}_{3}$ the rate constant $k_{5}$ is remarkably higher, which is also visible in concentration-time curve of HMF in Fig. 7. The parallel reaction of HMF to LA+FA is in the case of $\mathrm{KCl}$ and $\mathrm{CaCl}_{2}$ slower than the reaction $\mathrm{HMF}$ to hydrochar, which is the opposite for the $\mathrm{FeCl}_{3}$ experiments.
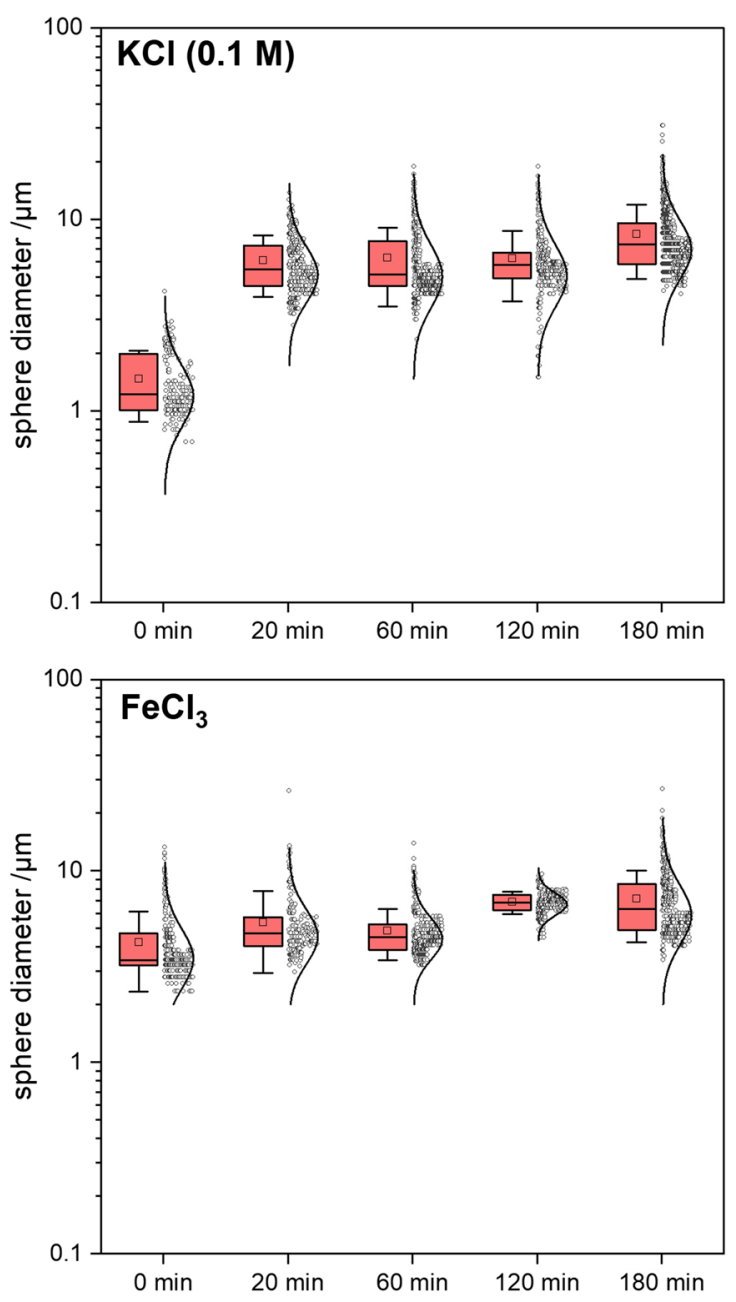

and lower boundaries outside of the box display the standard deviation. Right to the box-plot a log-transformed normal distribution of the particle diameter is displayed

\subsection{Comparison of formation rate and particle size}

To allow for a better comparison of the growth kinetics of the spheres under different conditions the mean sphere diameter is plotted against time in Fig. 8. The results of a previous publication, which were produced with the same equipment and conditions but without the use of salts are displayed as reference [9]. With this representation it can be highlighted that added salts remarkably accelerate the growth of the particles compared to neutral (without salts) conditions, and that after $20 \mathrm{~min}$ of reaction almost no differences can be distinguished between the variants. The figure additionally includes the reaction rate constant for the formation of hydrochar from $\operatorname{HMF}\left(k_{5}\right)$ right to the last measured point of a variant. By displaying the values in this figure comparison of growth and formation rates 


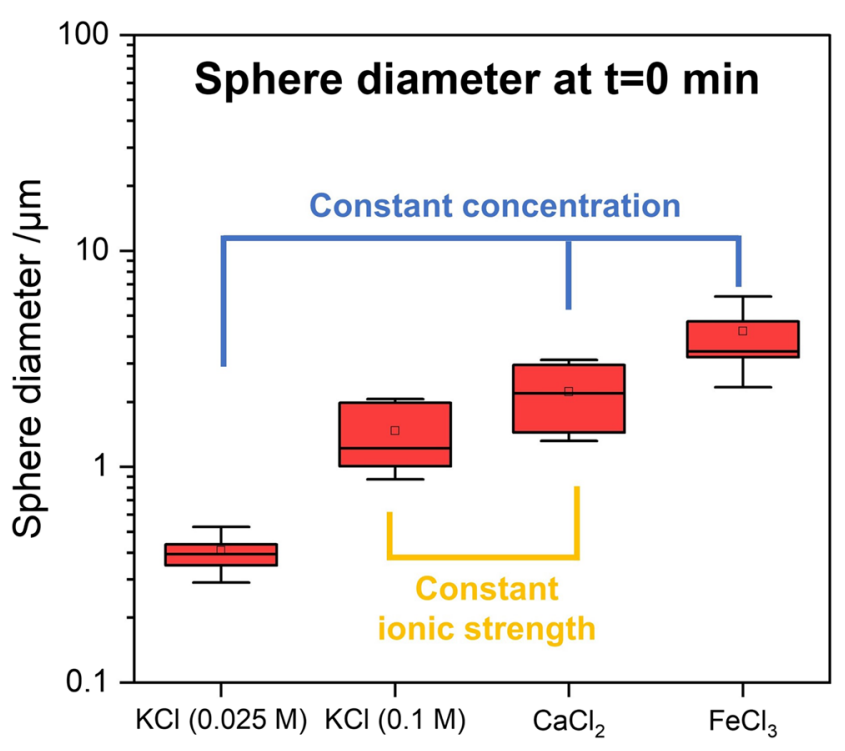

Fig. 6 Box-plot of the sphere diameter measured at $t=0 \mathrm{~min}$ for four different salts. shows the mean value. The height of the box-plot displays the lower 25 and upper 75 percentiles. The horizontal line in the box shows the median. The upper and lower boundaries outside of the box display the standard deviation

becomes more intuitive. Remarkably, the variant without salts (w/o) has almost the same reaction rate constant as the $\mathrm{KCl}$ variants, although their particle size differs remarkably. On the other side, $\mathrm{FeCl}_{3}$ increased the reaction rate constant, however without affecting the final size of the particles, compared to the other salts.

\subsection{ICP-OES analysis of liquid samples}

After quenching the reactor, the salt concentration was measured in the process water. The recovery rate based on the initial concentration is displayed in Table 4. It can be observed that despite the formation of hydrochar in course of the reaction the concentration of salts remains rather constant at approximately $100 \%$ recovery. The salts

Table 2 Carbon content of selected hydrochars

\begin{tabular}{llll}
\hline Salt & Reaction time & C-content $(\%)$ & SD \\
\hline $\mathrm{KCl}(0.025 \mathrm{M})$ & $20 \mathrm{~min}$ & 64.8 & 4.36 \\
$\mathrm{KCl}(0.025 \mathrm{M})$ & $180 \mathrm{~min}$ & 65.1 & 4.41 \\
$\mathrm{KCl}(0.1 \mathrm{M})$ & $30 \mathrm{~min}$ & 67.9 & 1.52 \\
$\mathrm{KCl}(0.1 \mathrm{M})$ & $180 \mathrm{~min}$ & 66.9 & 0.06 \\
$\mathrm{CaCl}_{2}$ & $20 \mathrm{~min}$ & 65.3 & 0.46 \\
$\mathrm{CaCl}_{2}$ & $180 \mathrm{~min}$ & 66.9 & 0.13 \\
$\mathrm{FeCl}_{3}$ & $20 \mathrm{~min}$ & 65.0 & 0.06 \\
$\mathrm{FeCl}_{3}$ & $180 \mathrm{~min}$ & 65.8 & 0.03 \\
\hline
\end{tabular}

The values represent the mean value out of two measurements. $S D$, standard deviation are therefore not significantly incorporated into the solid particles.

\subsection{Effect of reactor stirring on the morphology}

Stirring the reactor did remarkably changed the morphology of the carbon spheres. While the non-stirred experiments resulted in an exhaustive spherical morphology, the stirred samples show a strongly disrupted morphology with very large merged agglomerates. In Fig. 9a, it can be observed that despite the formation of large agglomerates small carbon spheres are present in the bulk. Figure 9b shows a large bulk of hydrochar with a size of approx. $220 \mu \mathrm{m}$ with a few spherical-shaped particles on the surface. In Fig. 9c, a large stretched particle with a length of approx. $100 \mu \mathrm{m}$ covered with a few spheres can be observed. A large bulk of hydrochar can be observed on top of Fig. 9d with diameter of approx. $110 \mu \mathrm{m}$, on the bottom a similar shaped stretched in as is Fig. 9c can be observed with a length of approx. $300 \mu \mathrm{m}$. Hydrochar particles that were produced while the reactor was stirred display more deviation from an ideal spherical shape as non-stirred hydorchars. Additionally, the particles agglomerate in huge bulks.

\subsection{Qualitative analysis of morphology}

The above-performed evaluation is mainly founded on the mean particle size, which probably creates the impression that the morphology of the particles consists of ideal-shaped spheres. However, quite the opposite is the case. To give a more balanced overview, the particles were further evaluated following the morphological particularities, which were formed by the bulk of many smaller spherical particles. The sketches were produced to better highlight the particularity of the given sample. The morphology of the spheres and their corresponding agglomerates is based on structures with different sizes and appearances. In Fig. 10a, a large sheet containing a huge amount of very small spheres can be observed. The spheres are in a range of approximately $1 \mu \mathrm{m}$. This structure can be found at the beginning of the reaction after the formation of the first spheres. In Fig. 10b, a middle-sized agglomerate of many fused spheres is illustrated, in which the former shape of the spherical subunits is only marginally apparent. This type of agglomerate can be found in the early stage of the reaction (between 20 and $60 \mathrm{~min}$ ). Figure 10c displays an assembly of larger particles surrounded by many small spheres. Figure $11 \mathrm{~d}$ shows a relatively huge agglomerate of merged spheres with approx. $10 \mu \mathrm{m}$ diameter, which is covered by small spheres that smashed into the large spheres. In Fig. 11e, a structure is displayed, which can be observed in many samples, especially in the middle and the end of the reaction. In here many interconnected, uniformly sized spheres are present over a large 
Table 3 Reaction rate constants $(k)$ for different reactions in the kinetic model for the four different salts

\begin{tabular}{llllll}
\hline $\mathrm{k}$ & Reaction & $\mathrm{KCl}$ & $\mathrm{KCl}$ & $\begin{array}{l}\mathrm{CaCl}_{2} \\
0.025 \mathrm{M}\end{array}$ & $\begin{array}{l}\mathrm{FeCl}_{3} \\
0.025 \mathrm{M}\end{array}$ \\
\hline$k_{1}$ & Fructose $\rightarrow$ HMF & $2.75 \mathrm{E}-01$ & $1.32 \mathrm{E}-01$ & $2.75 \mathrm{E}-01$ & - \\
$k_{2}$ & Fructose $\rightarrow$ Furfural + FA & $1.34 \mathrm{E}-02$ & $3.37 \mathrm{E}-02$ & $1.73 \mathrm{E}-02$ & - \\
$k_{3}$ & Fructose $\rightarrow$ Glucose & 0 & 0 & $1.10 \mathrm{E}-03$ & - \\
$k_{4}$ & Fructose $\rightarrow$ Residue & $1.14 \mathrm{E}-01$ & $3.36 \mathrm{E}-01$ & $1.80 \mathrm{E}-01$ & - \\
$k_{5}$ & HMF $\rightarrow$ Hydrochar & $2.67 \mathrm{E}-02$ & $2.79 \mathrm{E}-02$ & $3.63 \mathrm{E}-02$ & $1.15 \mathrm{E}-01$ \\
$k_{6}$ & HMF $\rightarrow$ LA + FA & $1.24 \mathrm{E}-02$ & $1.67 \mathrm{E}-02$ & $2.10 \mathrm{E}-02$ & $1.32 \mathrm{E}-01$ \\
$k_{7}$ & HMF $\rightarrow$ Residue & $1.00 \mathrm{E}-03$ & 0 & $2.80 \mathrm{E}-03$ & $1.35 \mathrm{E}-02$ \\
$k_{8}$ & Furfural $\rightarrow$ Hydrochar & $2.22 \mathrm{E}-02$ & $2.13 \mathrm{E}-02$ & $1.74 \mathrm{E}-02$ & $5.25 \mathrm{E}-02$ \\
$k_{9}$ & Glucose $\rightarrow$ Residue & $4.59 \mathrm{E}-01$ & $9.20 \mathrm{E}-03$ & $7.22 \mathrm{E}-02$ & $1.00 \mathrm{E}-03$ \\
$k_{10}$ & Residue $\rightarrow$ Hydrochar & $7.00 \mathrm{E}-04$ & $1.60 \mathrm{E}-03$ & $3.30 \mathrm{E}-03$ & $2.30 \mathrm{E}-03$
\end{tabular}

Unit: $\min ^{-1}$
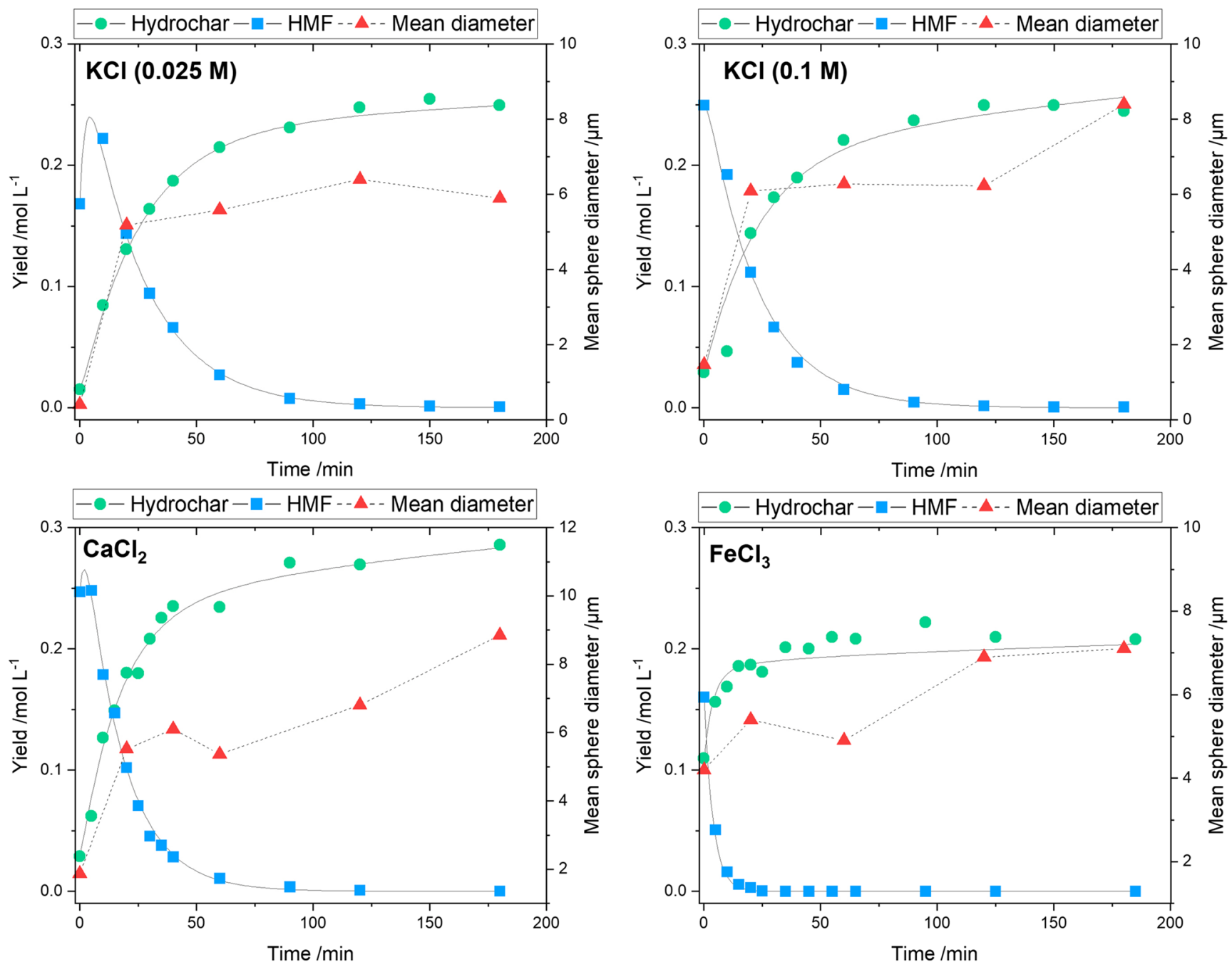

Fig. $7 Y$-axis (left): Yield in dependence of reaction time. $Y$-axis (right): Mean sphere diameter in dependence of reaction time. Model-lines for the concentration-time plot are derived by the kinetic model. Mean-diameter points are connected by straight lines (without model) 
Fig. 8 Mean sphere diameter in dependence of reaction time for different electrolytes. w/o, without salts. Data were taken from Jung et al. [9]. The number right to the last data point represents the formation rate of hydrochar from $\operatorname{HMF}\left(k_{5}\right)$. The rate constant $\left(k_{5}\right)$ for the variant w/o has been calculated in the cited article and has another subscript in the corresponding publication

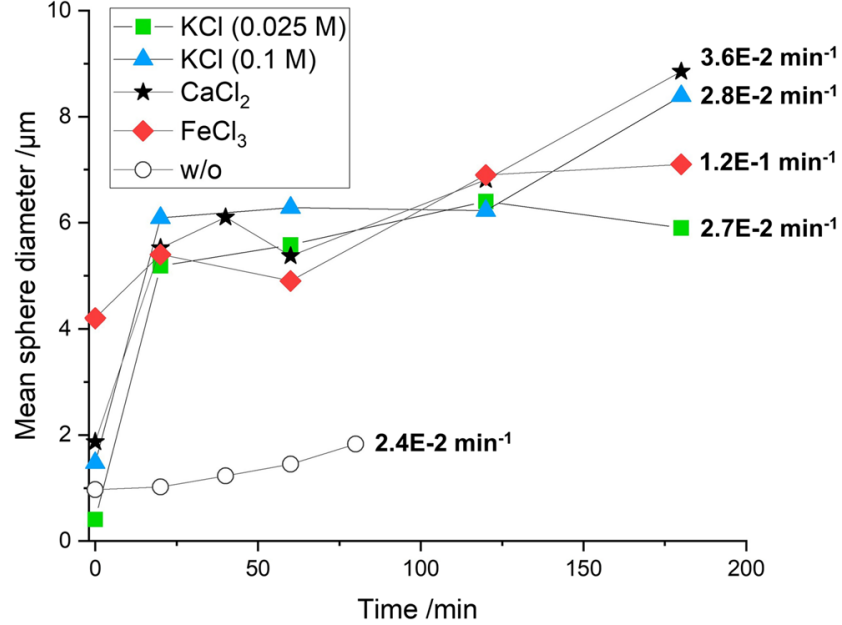

Table 4 Recovery of salts in \% in process water with different reaction time
Fig. 9 SEM pictures of hydrochar produced in a stirred batch reactor. a With $\mathrm{CaCl}_{2}$. b without salt. c with $\mathrm{CaCl}_{2}$. d with $\mathrm{CaCl}_{2}$
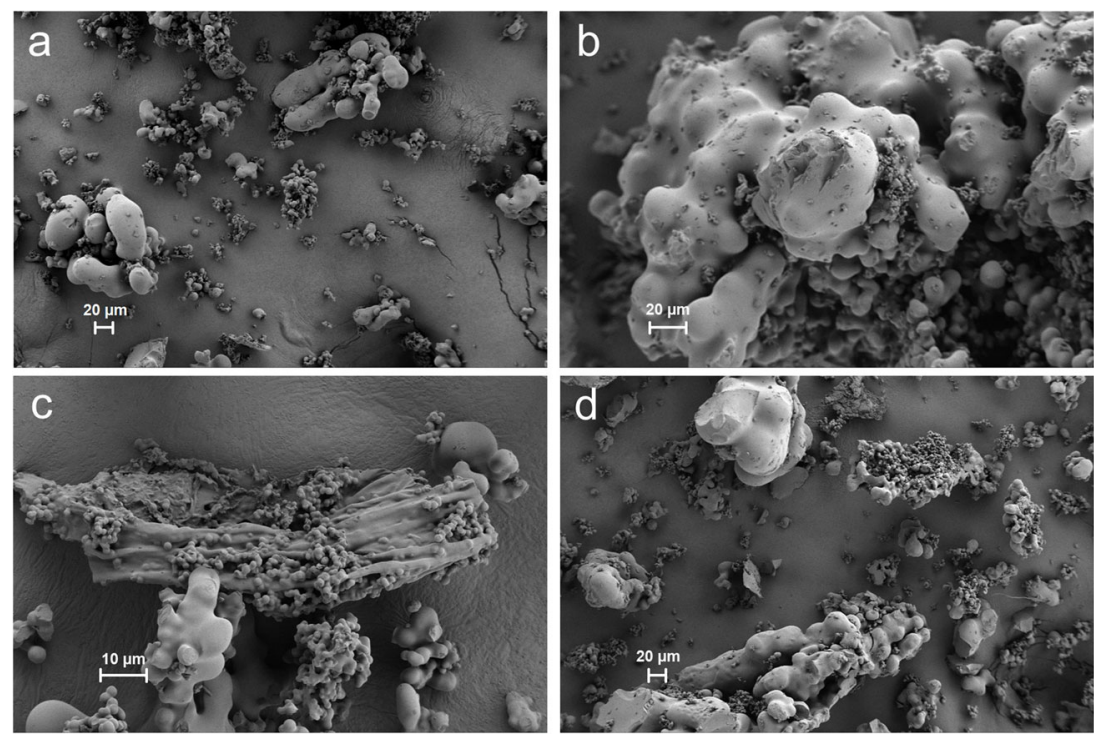
Fig. 10 SEM pictures and sketches of hydrochar at different conditions. a $\mathrm{KCl}(0.01$ M) $t=0 \mathrm{~min}$. b $\mathrm{CaCl}_{2}(0.025$

M) $t=40 \min \mathbf{c ~} \mathrm{CaCl}_{2}(0.025$

M) $t=0 \mathrm{~min}$
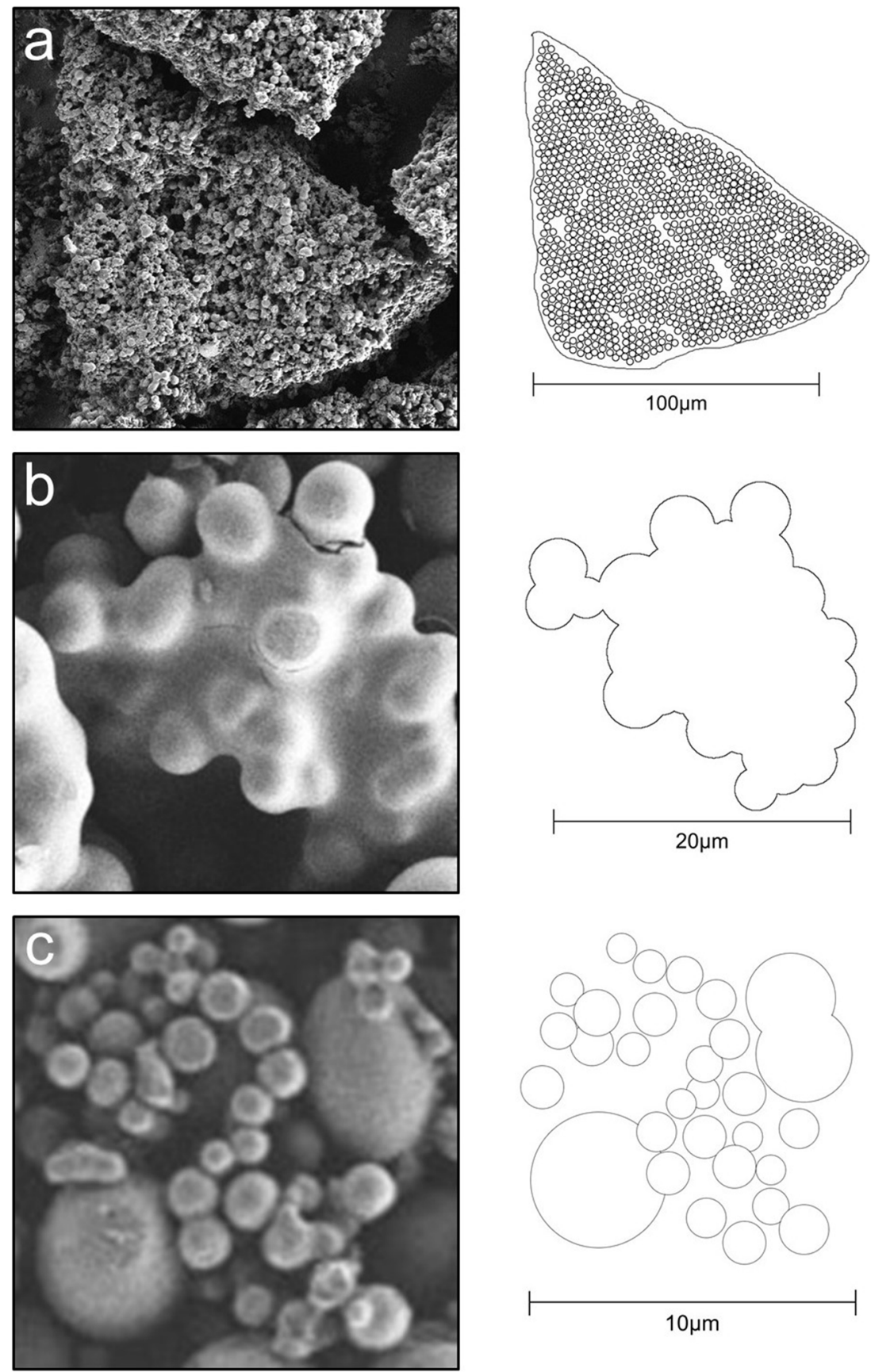

window. This appearance is very typical for the morphology as large areas are usually covered with this type. In contrast to that, the structure in Fig. 11f appears mostly punctual and displays the largest sort of particles, which were observed in the sample set of this article. Those particles are superlarge compared to the others and only appear at the end of the reaction. The particles exhibit no distinctive spherical morphology.

\section{Discussion}

The characteristic morphology of the spheres has been described in terms of quantitative and qualitative factors. The most dominant observation is that the added salts highly affect the growth of the particles, resulting in very big particles compared to experiments without such additives, this is in agreement with many previous studies [9, 28-33]. 
Fig. 11 SEM pictures and skteches of hydrochar at different conditions. d: $\operatorname{KCl}(0.025 \mathrm{M}) t=180 \mathrm{~min}$. e: $\mathrm{KCl}(0.01 \mathrm{M}) t=40 \mathrm{~min}$ f: $\mathrm{CaCl}_{2}(0.025 \mathrm{M}) t=120 \mathrm{~min}$.
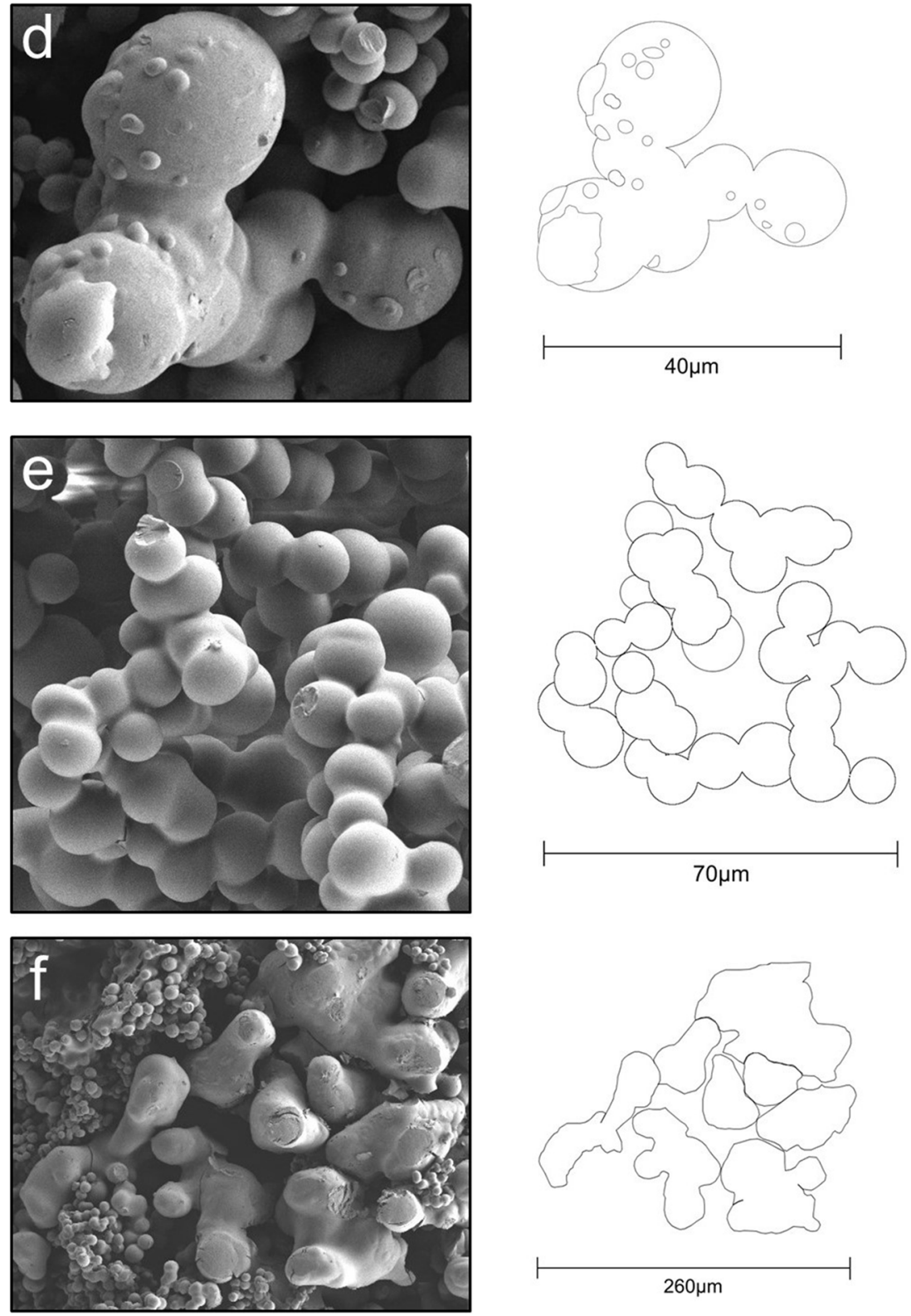

Although the system is very complex, with a variety of factors that influence the growth of the particles, such as time, temperature, concentration $[19,20]$ and additives, it can be concluded from the literature that carbon spheres produced without additives usually have a mean diameter in a range between $100 \mathrm{~nm}$ and $2 \mu \mathrm{m}$ [9, 19, 20, 22, 48, 49], whereas the usage of additives, such as salts or acids, results in larger particles that vary between 1 and $15 \mu \mathrm{m}[9,29,30$, 32-34].

As mentioned in the introduction, there is no clarity about the growth mechanism of these particles under the influence of salts. The major growth of the particles takes place at the beginning of the reaction in the same time range where the particles form. Between 20 and $180 \mathrm{~min}$, the particles do not remarkably increase in size and almost no differences can be detected among the different additives. Therefore it can be assumed that the average particle size of 6 to $9 \mu \mathrm{m}$ is a thermodynamic stable state and that the salts only affected the growth rate. Similar results were observed by $\mathrm{Li}$ et al., where the mean particle size remained constant for longer reaction times [37]. Also, the formation of the particles is rather quick compared to the reaction time applied in other studies, which varies between 6 and 48 h [12, 21, 28, 31, 32, 50-53]. However, the kinetics of hydrochar formation follows an Arrhenius temperature dependency [11]; therefore, longer reaction times are expected for lower 
temperatures $\left(<200{ }^{\circ} \mathrm{C}\right)$. Additionally, under the most commonly used saccharides, fructose converts remarkably faster than glucose and sucrose [54].

However, a key question of this work is to work out if the formation rate of hydrochar is correlated to the growth rate. After the heating phase $(t=0 \mathrm{~min})$ the differences between the salts are most visible (Fig. 6). A large difference can be found comparing both $\mathrm{KCl}$ trials, where a remarkable difference in particle size can be observed, although the formation rate is almost the same (2.7E- 2 compared to $2.8 \mathrm{E}$ $2 \min ^{-1}$ ). This can be a strong hint that the salt has an impact on the growth rate but not on the reaction rate, thus advocating for a growth mechanism that is not a result of higher reaction rates. The differences in particle size can be explained by the higher ionic strength of $\mathrm{KCl}$ at 0.1 M. At constant ionic strength, which is the case for $\mathrm{CaCl}_{2}$ and $\mathrm{KCl}(0.1 \mathrm{M})$ the difference in mean particle size at $t=0 \mathrm{~min}$ is very low, and the formation rates differ slightly. The effect of the ionic strength can be derived by the DLVO theory, which predicts reduced repulsive forces after a decrease in Debye length [55]. In other words, the higher the ionic strength, the lower is the Debye length, which in consequence accelerates the coagulation of the particles.

Another interesting observation can be made by comparing the results to neutral conditions. In a previous publication[9] almost identical experiments have been performed without salts. The absence of salts resulted in remarkable smaller particles, with a mean diameter between 1 and $2 \mu \mathrm{m}$ (Fig. 8). Despite those differences in particle size the reaction rate under neutral conditions $\left(2.4 \mathrm{E}-2 \mathrm{~min}^{-1}\right)$ only slightly differs compared to the $\mathrm{KCl}(2.7 \mathrm{E}-2$ and $2.8 \mathrm{E}-$ $2 \mathrm{~min}^{-1}$ ) experiments. Again it can be assumed that the reaction rate has no impact on the growth rate.

The results obtained by $\mathrm{FeCl}_{3}$ are difficult to interpret. Especially at the beginning of the reaction $(t=0 \mathrm{~min})$ the particles have already reached a high mean diameter and have been formed with a higher reaction rate compared to the other experiments. Those results at $t=0 \mathrm{~min}$ do not deliver any strong argument in favor of one of the two hypotheses.

The acceleration of the reactions $\left(k_{5}, k_{6}\right)$ in $\mathrm{FeCl}_{3}$ can be attributed due to its role as lewis acid, causing the formation of a complex with water molecules. The complex acts a cationic acid by splitting off a proton [56]. Consequently, the $\mathrm{pH}$ value decreases, and typical Brønsted-acid catalysis of the dehydration, polycondensation, and rehydration reactions take place $[10,57]$. At a certain proton concentration, the rehydration of HMF to LA is faster than the polycondensation to hydrochar [10]. As a result, the final $(t=180 \mathrm{~min})$ yield of hydrochar is lower compared to the other experiments.
The recovery of the salts in the process water is almost close to $100 \%$, therefore it can be assumed that the salts are not significantly incorporated into the particles, which has also been observed in another study from Zhao et al. [31].

So far, the results do not indicate that salts are increasing the particle size by catalyzing the hydrochar formation. The reaction-controlled growth, which is often mentioned in this context, probably only applies to the primary particles that form during the polycondensation of HMF [7], but without having an impact on the particles size. It is more likely that the second hypothesis mentioned in the introduction is true. This means that coagulation of the emulsion-like droplets is a major driver for the growth of the particles. This conclusion initiated the idea, that those particles must be vulnerable to mechanical stress, such as is the case in a stirred reactor. SEM pictures in Fig. 9 are in agreement with that conception. Stirring the reactor partly destroyed the spherical shape of the particles. One can therefore regard these particles as droplets of an emulsion under hydrothermal conditions. As soon as the droplets get in contact with the stirring element they get smudged and form oversized particles. Due to the very low viscosity of water under hydrothermal conditions the theoretical power need is very low at $2.9 \mathrm{E}-04 \mathrm{~W}$, therefore the agitator exhibits a force of $1.2 \mathrm{E}-03 \mathrm{~N}$ if the systems consist of pure water. However, the power supply was not monitored during the reaction, therefore it cannot be said if and how the rheological properties of the system changed when hydrochar was formed. Intuitively, it has to be assumed that the hydrochar particles, if they are not purely solid, are highly viscous droplets similar to pitch. Therefore it is very likely that the agitator force is by magnitudes higher than the value calculated for pure water. To the best of our knowledge, we found one comparable article. Su et al. also observed disturbed spherical particles at $400 \mathrm{rpm}$ [58]. Samples at 0 and $200 \mathrm{rpm}$ showed no difference in morphology. They hypothesized that stirring the reactor at $400 \mathrm{rpm}$ disorganized a so-called self-assembly process, resulting in disturbed particles. This effect does not count for the entire bulk of hydrochar, as we could also observe spots with normally shaped spherical particles in the stirred samples.

But also the qualitative analysis of the morphology is in agreement with the concept of emulsion-like droplets. Figure $11 \mathrm{~d}$ shows a huge particle with little spheres smashed on the surface, probably caused by Ostwald ripening (OR). $\mathrm{OR}$ is defined as the growth of larger particles at the expense of smaller ones [59]. Figure 11b shows a larger particle which is formed by the fusion of many smaller spheres, and Fig. 11e shows many little spheres in a state of partial coagulation that forms a larger structure. All these observations together contribute to the hypothesis that these particles behave like droplets. However, one can 
also find arguments against that concept. Firstly, if the particles are droplets, why does it look like that the growth of the particles slows down after $20 \mathrm{~min}$ and the sphere size remains rather constant until $180 \mathrm{~min}$ ? Simple ongoing coagulation, further increasing the size, obviously did not take place. Why is it that so many footages of the particles show them in a state of partial coagulation? A simple liquid droplet seems to be too much simplified. One possible explanation could be that the particles mature with longer reaction time, by cross-linking reactions inside of the particles, inducing some sort of solidification. It is also possible that hydrochar has similar properties to carbonaceous mesophase. The term defines a material, whose state of matter is an intermediate between solid and liquid $[60,61]$. In this field of research, coalescence is widely recognized as a growth mechanism [62-64]. The models used to describe those systems can probably serve as a good foundation or inspiration for better modeling of the carbon spheres during HTC.

\section{Conclusions}

The present study has a focus on the growth and formation mechanism of hydrochar, and its interactions. The use of a kinetic model for the sake of measuring reaction rates is a promising tool for the evaluation of this research questions. Using this approach it could be worked out that the added salts did remarkably alter the size of the particles, but did not increase the formation rate significantly. This effect is more obvious for $\mathrm{KCl}$ and $\mathrm{CaCl}_{2}$ than for $\mathrm{FeCl}_{3}$. In general, the major growth of the particles took place at the beginning of the reaction, in the same time range, where the formation takes place. The results show that between 20 and $180 \mathrm{~min}$ the particles reached a rather stable particle size with few differences regarding the type of salt and the ionic strength. Therefore it was concluded that the salts only increase the growth rate but the final particle size was independent from the salt, thus having a kinetic impact. Experiments with a focus on ionic strength show that its impact is related to the beginning of the reaction. Although the database is very small, the results confirm that a constant ionic strength leads to a rather similar particle size distribution and mean diameter. The usage of an anchor-type stirrer induced mechanical stress, which results in squashed particles and huge agglomerates. In summary, the results support the hypothesis that the growth of the particles takes place via coalescence of droplets on the basis of the DLVO theory. However, solidification of the particles in course of the reaction is likely, therefore it can be assumed that the state of matter is an intermediate between solid and liquid, probably similar to mesophase pitch. Controlling particle size is an important milestone for engineering purposes. The reaction conditions in this work lead to a fast growth of particles with salts. Setting a lower ionic strength in the reaction medium (by a lower salt concentration $(<0.025 \mathrm{M})$ ) could decrease the growth rate and enable more control of the particle size.

Supplementary Information The online version contains supplementary material available at https://dx.doi.org/10.1007/s13399-021-01782-6.

Acknowledgements We thank Ekatarina Ovsyannikova and Gero Becker for performing the ICP-OES measurements, and Nattacha Paksung for her help during the HTC experiments.

Author contribution Dennis Jung: writing original draft, experiments, conceptualization, methodology, visualization, investigation, software Gözde Duman: experiments, methodology, review and editing Michael Zimmermann: analysis, review and editing

Andrea Kruse: supervision, project administration, funding acquisition, review and editing

Jale Yanik: supervision, project administration, funding acquisition, review and editing

Funding Open Access funding enabled and organized by Projekt DEAL. This research was funded by the Federal Ministry of Education and Research of Germany in the framework of the ERA-Net Medwaste initiative, grant number 01DH17035. Dennis Jung received a generous grant from the Paul and Yvonne Gillet Foundation,

Conflict of interest The authors declare no competing interests.

Open Access This article is licensed under a Creative Commons Attribution 4.0 International License, which permits use, sharing, adaptation, distribution and reproduction in any medium or format, as long as you give appropriate credit to the original author(s) and the source, provide a link to the Creative Commons licence, and indicate if changes were made. The images or other third party material in this article are included in the article's Creative Commons licence, unless indicated otherwise in a credit line to the material. If material is not included in the article's Creative Commons licence and your intended use is not permitted by statutory regulation or exceeds the permitted use, you will need to obtain permission directly from the copyright holder. To view a copy of this licence, visit http://creativecommons. org/licenses/by/4.0/.

\section{References}

1. Libra JA, Ro KS, Kammann C, Funke A, Berge ND, Neubauer Y, Titirici M-M, Fühner C, Bens O, Kern J, Emmerich K-H (2011) Hydrothermal carbonization of biomass residuals: a comparative review of the chemistry, processes and applications of wet and dry pyrolysis. Biofuels 2(1):71-106. https://doi.org/10.4155/bfs.10.81

2. Funke A, Ziegler F (2010) Hydrothermal carbonization of biomass: A summary and discussion of chemical mechanisms for process engineering. Biofuels Bioprod Bioref 4(2):160-177. https://doi.org/10.1002/bbb.198 
3. Jian Z, Xing Z, Bommier C, Li Z, Ji X (2016) Hard Carbon Microspheres: Potassium-Ion Anode Versus Sodium-Ion Anode. Adv Energy Mater 6(3):1-5. https://doi.org/10.1002/aenm.201501874

4. Gomez-Martin A, Martinez-Fernandez J, Ruttert M, Winter M, Placke T, Ramirez-Rico J (2019) Correlation of Structure and Performance of Hard Carbons as Anodes for Sodium Ion Batteries. Chem Mater 31:7288-7299. https://doi.org/10.1021/acs. chemmater.9b01768

5. Dou X, Hasa I, Saurel D, Vaalma C, Wu L, Buchholz D, Bresser D, Komaba S, Passerini S (2019) Hard carbons for sodium-ion batteries: Structure, analysis, sustainability, and electrochemistry. Materials Today 23(March):87-104. https://doi.org/10.1016/j.mattod.2018.12.040

6. Wang Q, Li H, Chen L, Huang X (2001) Monodispersed hard carbon spherules with uniform nanopores. Carbon 39(14):22112214. https://doi.org/10.1016/S0008-6223(01)00040-9

7. Patil SKR, Lund CRF (2011) Formation and Growth of Humins via Aldol Addition and Condensation during AcidCatalyzed Conversion of 5-Hydroxymethylfurfural. Energy Fuels 25(10):4745-4755. https://doi.org/10.1021/ef2010157

8. Patil SKR, Heltzel J, Lund CRF (2012) Comparison of structural features of humins formed catalytically from glucose, fructose, and 5-hydroxymethylfurfuraldehyde. Energy Fuels 26(8):52815293. https://doi.org/10.1021/ef3007454

9. Jung D, Zimmermann M, Kruse A (2018) Hydrothermal Carbonization of Fructose: Growth Mechanism and Kinetic Model. ACS Sustain Chem Eng 6(11):13877-13887. https://doi.org/10.1021/acssuschemeng.8b02118

10. Jung D, Körner P, Kruse A (2019) Kinetic study on the impact of acidity and acid concentration on the formation of 5hydroxymethylfurfural (HMF), humins, and levulinic acid in the hydrothermal conversion of fructose. Biomass Conversion and Biorefinery. https://doi.org/10.1007/s13399-019-00507-0

11. Jung D, Körner P, Kruse A (2020) Calculating the Reaction Order and Activation Energy for the Hydrothermal Carbonization of Fructose. Chemie Ingenieur Technik 92(6):692-700. https://doi.org/10.1002/cite.201900093

12. Baccile N, Laurent G, Babonneau F, Fayon F, Titirici M-M, Antonietti M (2009) Structural Characterization of Hydrothermal Carbon Spheres by Advanced Solid-State MAS13C NMR Investigations. J Phys Chem C 113(22):9644-9654. https://doi.org/10.1021/jp901582x

13. Filiciotto L, Balu AM, Romero AA, Angelici C, van der Waal JC, Luque R (2019) Reconstruction of humins formation mechanism from decomposition products: A GC-MS study based on catalytic continuous flow depolymerizations. Mol Catal 479(August):110564. https://doi.org/10.1016/j.mcat.2019.110564

14. Shen H, Shan H, Liu L (2020) Evolution Process and Controlled Synthesis of Humins with 5-Hydroxymethylfurfural (HMF) as Model Molecule. ChemSusChem 13(3):513-519. https://doi.org/10.1002/cssc.201902799

15. Shi N, Liu Q, Cen H, Ju R, He X, Ma L (2019) Formation of humins during degradation of carbohydrates and furfural derivatives in various solvents. Biomass Conversion and Biorefinery. https://doi.org/10.1007/s13399-019-00414-4

16. Shi N, Liu Q, Ju R, He X, Zhang Y, Tang S, Ma L (2019) Condensation of $\alpha$-Carbonyl Aldehydes Leads to the Formation of Solid Humins during the Hydrothermal Degradation of Carbohydrates. ACS Omega 4(4):7330-7343. https://doi.org/10.1021/acsomega.9b00508

17. Tsilomelekis G, Orella MJ, Lin Z, Cheng Z, Zheng W, Nikolakis V, Vlachos DG (2016) Molecular structure, morphology and growth mechanisms and rates of 5-hydroxymethyl furfural (HMF) derived humins. Green Chem. 18(7):19831993. https://doi.org/10.1039/C5GC01938A, http://pubs.rsc.org/ en/content/articlehtml/2016/gc/c5gc01938a

18. Volpe M, Fiori L (2017) From olive waste to solid biofuel through hydrothermal carbonisation: The role of temperature and solid load on secondary char formation and hydrochar energy properties. J Anal Appl Pyrol 124:63-72. https://doi.org/10.1016/j. jaap.2017.02.022, http://www.sciencedirect.com/science/article/ pii/S0165237016308415

19. Chen C, Sun X, Jiang X, Niu D, Yu A, Liu Z, Li JG (2009) A Two-Step Hydrothermal Synthesis Approach to Monodispersed Colloidal Carbon Spheres. Nanoscale Res Lett 4(9):971-976. https://doi.org/10.1007/s11671-009-9343-5, http:// www.nanoscalereslett.com/content/4/9/971

20. Qi Y, Zhang M, Qi L, Qi Y (2016) Mechanism for the formation and growth of carbonaceous spheres from sucrose by hydrothermal carbonization. RSC Advances 6(25):20814-20823. https://doi.org/10.1039/C5RA26725K, http://xlink.rsc.org/? DOI $=$ C5RA26725K

21. Romero-Anaya AJ, Ouzzine M, Lillo-Ródenas MA, LinaresSolano A (2014) Spherical carbons: Synthesis, characterization and activation processes. Carbon 68:296-307. https://doi.org/10. 1016/j.carbon.2013.11.006

22. Liu S, Wang $X$, Zhao H, Cai W (2015) Micro/nanoscaled carbon spheres based on hydrothermal carbonization of agarose. Colloids Surf A Physicochem Eng Asp 484:386-393. https://doi.org/10.1016/j.colsurfa.2015.08.019

23. Zhang $M$, Yang $H$, Liu Y, Sun $X$, Zhang D, Xue D (2012) Hydrophobic precipitation of carbonaceous spheres from fructose by a hydrothermal process. Carbon 50(6):2155-2161. https://doi.org/10.1016/j.carbon.2012.01.024

24. Sulistya E, Hui-Hui L, Attenborough NK, Pourshahrestani S, Kadri NA, Zeimaran E, Razak NAA, Amini Horri B, Salamatinia B (2020) Hydrothermal synthesis of carbon microspheres from sucrose with citric acid as a catalyst: physicochemical and structural properties. J Taibah Univ Sci 14(1):1042-1050. https://doi.org/10.1080/16583655.2020.1794566

25. Qi Y, Song B, Qi Y, Afonso CAM, Brown NMD, Hattori H, Arai K, Kaliaguine S, Zhao D, Lu AH, Chun C, Zhao D (2016) The roles of formic acid and levulinic acid on the formation and growth of carbonaceous spheres by hydrothermal carbonization. RSC Adv 6(104):102428-102435. https://doi.org/10.1039/C6RA21312J, http://xlink.rsc.org/?DOI=C6RA21312J

26. Latham KG, Jambu G, Joseph SD, Donne SW (2014) Nitrogen doping of hydrochars produced hydrothermal treatment of sucrose in $\mathrm{H} 2 \mathrm{O}, \mathrm{H} 2 \mathrm{SO} 4$, and $\mathrm{NaOH}$. ACS Sustain Chem Eng 2(4):755764. https://doi.org/10.1021/sc4004339. arXiv:1411.7823v1

27. Cai H, Lin X, Tian L, Luo X (2016) One-Step Hydrothermal Synthesis of Carbonaceous Spheres from Glucose with an Aluminum Chloride Catalyst and Its Adsorption Characteristic for Uranium(VI). Ind Eng Chem Res 55(36):9648-9656. https://doi.org/10.1021/acs.iecr.6b02540

28. Zha G, Yu L (2016) Influence of sucrose solution's pH on hydrothermally synthesized carbon microspheres. Fullerenes Nanotubes Carbon Nanostruct 24(2):139-143. https://doi.org/10. 1080/1536383X.2015.1124419

29. Qiao L, Chen J, Ying Y, Zheng JW, Jiang L (2013) Influence of $\mathrm{NH} 4+$ on the preparation of carbonaceous spheres by a hydrothermal process. J Mater Sci 48(9):3341-3346. https://doi.org/10.1007/s10853-012-7023-9

30. Yang H, Wang G, Ding N, Yin C, Chen Y (2016) Size-controllable synthesis of carbon spheres with assistance of metal ions. Synth Met 214:1-4. https://doi.org/10.1016/j.synthmet.2016.01.011 
31. Zhao H, Lu X, Wang Y, Sun B, Wu X, Lu H (2017) Effects of additives on sucrose-derived activated carbon microspheres synthesized by hydrothermal carbonization. J Mater Sci 52(18):10787-10799. https://doi.org/10.1007/s10853-017-1258-4

32. Yang L, Hu M, Lv Q, Zhang H, Yang W, Lv R (2020) Salt and sugar derived high power carbon microspheres anode with excellent low-potential capacity. Carbon 163(March):288-296. https://doi.org/10.1016/j.carbon.2020.03.021

33. Zhang $C$, Lin $S$, Peng J, Hong $Y$, Wang $Z$, Jin $X$ (2017) Preparation of highly porous carbon through activation of $\mathrm{NH}<\mathrm{sub}>4</ \mathrm{sub}>\mathrm{Cl}$ induced hydrothermal microsphere derivation of glucose. RSC Advances 7(11):64866491. https://doi.org/10.1039/C6RA26141H, http://xlink.rsc.org/? DOI=C6RA26141H

34. Titirici MM, Antonietti M, Thomas A (2006) A generalized synthesis of metal oxide hollow spheres using a hydrothermal approach. Chem Mater 18(16):3808-3812. https://doi.org/10. $1021 / \mathrm{cm} 052768 \mathrm{u}$

35. Ming J, Wu Y, Liang G, Park J-B, Zhao F, Sun Y-K (2013) Sodium salt effect on hydrothermal carbonization of biomass: a catalyst for carbon-based nanostructured materials for lithium-ion battery applications. Green Chem 15(10):27222726. https://doi.org/10.1039/c3gc40480c, http://xlink.rsc.org/? DOI $=\mathrm{c} 3 \mathrm{gc} 40480 \mathrm{c}$

36. Li S, Liang F, Wang J, Zhang H, Zhang S (2017) Preparation of mono-dispersed carbonaceous spheres via a hydrothermal process. Adv Powder Technol 28:2648-2657. https://doi.org/10.1016/j.apt.2017.07.017, https://ac.els-cdn. com/S0921883117303023/1-s2.0-S0921883117303023-main. pdf?_tid=f055e7da-ff81-11e7-bb82-00000aacb360\& acdnat=1516632109_bfa9ca5410dbdaa00b71d118a2a69fb4

37. Li M, Li W, Liu SX (2012) Control of the morphology and chemical properties of carbon spheres prepared from glucose by a hydrothermal method. J Mater Res 27(8):1117-1123. https://doi.org/10.1557/jmr.2011.447

38. Inada M, Enomoto N, Hojo J, Hayashi K (2017) Structural analysis and capacitive properties of carbon spheres prepared by hydrothermal carbonization. Adv Powder Technol 28(3):884889. https://doi.org/10.1016/J.APT.2016.12.014, http://www. sciencedirect.com/science/article/pii/S0921883116303867

39. Ionic strength I (2014) In: The IUPAC Compendium of Chemical Terminology. International Union of Pure and Applied Chemistry (IUPAC), Research Triangle Park. https://goldbook.iupac.org/ terms/view/I03180

40. (2001). Engineering ToolBox. https://www.engineeringtoolbox. com

41. Kraume M (2012) Transportvorgänge in der Verfahrenstechnik. Springer, Berlin. https://doi.org/10.1007/978-3-642-25149-8

42. Zlokarnik M (1999) Rührtechnik. Springer, Berlin. https://doi.org/ 10.1007/978-3-642-58635-4

43. Kabyemela BM, Adschiri T, Malaluan RM, Arai K (1999) Glucose and Fructose Decomposition in Subcritical and Supercritical Water: Detailed Reaction Pathway, Mechanisms, and Kinetics. Ind Eng Chem Res 38:2888-2895. https://doi.org/10.1021/ie9806390

44. Fachri BA, Abdilla RM, Bovenkamp HHVD, Rasrendra CB, Heeres HJ (2015) Experimental and Kinetic Modeling Studies on the Sulfuric Acid Catalyzed Conversion of d-Fructose to 5-Hydroxymethylfurfural and Levulinic Acid in Water. ACS Sustain Chem Eng 3(12):3024-3034. https://doi.org/10.1021/acssuschemeng.5b00023

45. Möller M, Harnisch F, Schröder U (2012) Microwave-assisted hydrothermal degradation of fructose and glucose in subcritical water. Biomass Bioenergy 39:389-398. https://doi.org/10.1016/j. biombioe.2012.01.036
46. Fusaro MB, Chagnault V, Postel D (2015) Reactivity of d-fructose and d-xylose in acidic media in homogeneous phases. Carbohydr Res 409:9-19. https://doi.org/10.1016/j.carres.2015.03.012

47. Swift TD, Bagia C, Choudhary V, Peklaris G, Nikolakis V, Vlachos DG (2014) Kinetics of homogeneous Brønsted acid catalyzed fructose dehydration and 5-hydroxymethyl furfural rehydration: A combined experimental and computational study. ACS Catal 4(1):259-267. https://doi.org/10.1021/cs4009495

48. Yao C, Shin Y, Wang LQ, Windisch CF, Samuels WD, Arey BW, Wang C, Risen WM, Exarhos GJ (2007) Hydrothermal dehydration of aqueous fructose solutions in a closed system. J Phys Chem C 111(42):15141-15145. https://doi.org/10.1021/jp0741881

49. Titirici M-M, Antonietti M, Baccile N (2008) Hydrothermal carbon from biomass: a comparison of the local structure from poly- to monosaccharides and pentoses/hexoses. Green Chem 10(11):1204. https://doi.org/10.1039/b807009a

50. Simsir H, Eltugral N, Karagoz S (2017) Hydrothermal carbonization for the preparation of hydrochars from glucose, cellulose, chitin, chitosan and wood chips via low-temperature and their characterization. Bioresour Technol 246:82-87. https://doi.org/ 10.1016/J.BIORTECH.2017.07.018, https://www.sciencedirect. com/science/article/pii/S0960852417311045

51. Van Zandvoort I, Wang Y, Rasrendra CB, Van Eck ERH, Bruijnincx PCA, Heeres HJ, Weckhuysen BM (2013) Formation, molecular structure, and morphology of humins in biomass conversion: Influence of feedstock and processing conditions. ChemSusChem 6(9):1745-1758. https://doi.org/10.1002/cssc.201300332

52. Zhang ZB, Liu YH, Cao XH, Liang P (2013) Sorption study of uranium on carbon spheres hydrothermal synthesized with glucose from aqueous solution. J Radioanal Nucl Chem 295(3):17751782. https://doi.org/10.1007/s10967-012-2247-3

53. Zhang Z, Wu G, Xu Z, Wu S, Gu L (2018) Adsorption of Methyl Blue onto uniform carbonaceous spheres prepared via an anionic polyacrylamide-assisted hydrothermal route. Mater Chem Phys 208:8-18. https://doi.org/10.1016/j.matchemphys.2018.01.025, http://linkinghub.elsevier.com/retrieve/pii/S0254058418300257

54. Steinbach D, Kruse A, Sauer J, Vetter P (2018) Sucrose Is a Promising Feedstock for the Synthesis of the Platform Chemical Hydroxymethylfurfural. Energies 11(3):645. https://doi.org/10.3390/en11030645, http://www.mdpi.com/ 1996-1073/11/3/645

55. Eastman J (2009) Colloid Stability. In: Colloid Science. Blackwell Publishing Ltd., Oxford, pp 36-49. https://doi.org/10.1002/ 9781444305395.ch3

56. Hofmann KA (1973) Hydrolyse der Kationen und basische Salze. In: Anorganische Chemie. Vieweg+Teubner, Wiesbaden, pp 603 606

57. Körner P, Jung D, Kruse A (2018) The effect of different Bronsted acids on the hydrothermal conversion of fructose to HMF. Green Chem 20(10):2231-2241. https://doi.org/10.1039/C8GC00435H, http://xlink.rsc.org/?DOI=C8GC00435H

58. Su J, Fang $C$, Yang $M$, Cheng $Y$, Wang $Z$, Huang $Z$, You C (2020) A controllable soft-templating approach to synthesize mesoporous carbon microspheres derived from Dxylose via hydrothermal method. J Mater Sci Technol 38:183-188. https://doi.org/10.1016/j.jmst.2019.03.050

59. McClements DJ (2009) Biopolymers in Food Emulsions, 1st edn. Elsevier Inc., Amsterdam. https://doi.org/10.1016/B978-0-12374195-0.00004-5

60. Yuan G, Cui Z (2020) Preparation, Characterization, and Applications of Carbonaceous Mesophase: A Review. In: Liquid Crystals and Display Technology. IntechOpen, p 13. https://www.intechopen. com/books/advanced-biometric-technologies/liveness-detectionin-biometrics https://www.intechopen.com/books/liquid-crystals- 
and-display-technology/preparation-characterization-and-applica tions-of-carbonaceous-mesophase-a- review

61. Eser S (1998) Carbonaceous Mesophase Formation and Molecular Composition of Petroleum Feedstocks, pp 147-155

62. Moriyama R, Hayashi JI, Suzuki K, Hiroshima T, Chiba T (2002) Analysis and modeling of mesophase sphere generation, growth and coalescence upon heating of a coal tar pitch. Carbon 40(1):5364. https://doi.org/10.1016/S0008-6223(01)00070-7

63. Bagheri SR, Gray MR, Shaw JM, McCaffrey WC (2012) In situ observation of mesophase formation and coalescence in catalytic hydroconversion of vacuum residue using a stirred hot-stage reactor. Energy and Fuels 26(6):3167-3178. https://doi.org/10.1021/ ef300321g

64. Chen L, Fei Y, Fan X, Jiang Z (2017) Coalescence of mesophase spheres and microstructure of graphitic carbon revealed by scanning electron microscopy. J Mater Sci 52(21):12663-12676. https://doi.org/10.1007/s10853-017-1364-3

Publisher's Note Springer Nature remains neutral with regard to jurisdictional claims in published maps and institutional affiliations. 